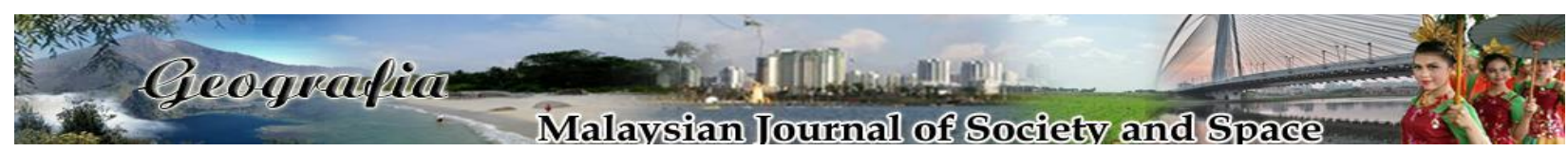

\title{
Peluang dan potensi Hutan Lipur Sungai Sedim sebagai produk eko pelancongan di Malaysia
}

\author{
Roslizawati Che Aziz, Nor Dalila Marican, Suriati Hamzah \\ Fakulti Hospitaliti, Pelancongan dan Kesejahteraan \\ Universiti Malaysia Kelantan
}

Correspondence: Roslizawati Che Aziz (email: roslizawati@umk.edu.my)

Received: 03 May 2020; Accepted: 26 January 2021; Published: 27 February 2021

\begin{abstract}
Abstrak
Kekuatan pelancongan Malaysia bukan sahaja terletak pada produk eko pelancongan malah destinasi yang ditawarkan juga murah, selamat dan mudah untuk dikunjungi. Malaysia mempunyai banyak tempat-tempat menarik bagi segmen eko pelancongan yang semakin di minati bukan sahaja di kalangan pelancong dalam negara malah juga dari luar negara yang ingin melihat keindahan alam sekitar serta menenangkan diri dari kesibukan kota. Produk eko pelancongan di Malaysia bukan sahaja di lihat sebagai satu aktiviti lasak tetapi juga sebagai pemangkin kepada kelestarian alam semulajadi. Hutan Lipur Sungai Sedim (HLSS), merupakan antara destinasi paling popular di daerah Kulim, Kedah yang mana menjadi lokasi kajian. Pemilihan HLSS adalah kerana ciri-ciri dan sumbangan masa depannya kepada semua pihak di kawasan berdekatan selain telah di angkat sebagai salah satu "LIMA destinasi pilihan di Asia Fasifik". Justeru, kajian ini membincangkan tentang peluang dan potensi HLSS sebagai salah satu produk eko pelancongan terkenal di serata dunia. Pendekatan kajian secara kualitatif telah digunakan dengan penglibatan seramai 59 orang responden. Hasil kajian menunjukkan bahawa HLSS berpotensi diiktiraf sebagai salah sebuah tarikan destinasi eko pelancongan terbaik di Malaysia di mana pelbagai keistimewaan seperti flora dan fauna, air terjun, Tree Top Walk, sukan air lasak dan sebagainya tersedia buat semua pelancong. Peluang diiktiraf sebagai produk eko pelancongan terunggul di Malaysia amat luas dengan menyediakan produk berfokus (niche-market), program inap desa (home-stay), pembangunan kemudahan dan infrastruktur serta pembangunan keusahawanan kecil dan sederhana.
\end{abstract}

Kata kunci: Hutan Lipur Sungai Sedim, eko pelancongan, pembangunan luar bandar, pelancongan lasak 


\title{
Potential and opportunities of Sungai Sedim Amenities Forest as ecotourism products in Malaysia
}

\begin{abstract}
The strength of Malaysia's tourism is not only in eco-tourism products but also the destinations offered which are cheap, safe and easy to visit. Malaysia has many interesting places for the growing eco-tourism segment not only among domestic consumers but also from overseas especially for those who want to see the beauty of the environment and to relax from the bustle of the city. Ecotourism products in Malaysia are not only seen as an activity but also as a catalyst for the sustainability of nature. Hutan Lipur Sungai Sedim (HLSS), one of the most popular destinations in Kulim district, Kedah, is the study area. The selection of HLSS is due to its features and future assistance to all nearby areas which has been recognized as one of the "FIVE preferred destinations in Asia Pacific". Thus, this study attempts to discover the opportunities and potential of HLSS as one of the most popular ecotourism products worldwide. Qualitative approach has been used in this study with the involvement of 59 respondents. The results show that HLSS has potential to be recognized as one of the best ecotourism destinations in Malaysia with various privileges such as flora and fauna, waterfalls, Tree Top Walk, rugged air sports and the like are available to everyone. Opportunities are recognized as Malaysia's leading ecotourism products by providing niche-market products, home-stay programs, infrastructure development and development as well as small and medium-sized entrepreneurship development.
\end{abstract}

Keywords: Hutan Lipur Sungai Sedim, eco tourism, rural development, adventure tourism

\section{Pengenalan}

Industri pelancongan di Malaysia merupakan antara sektor terpenting bukan sahaja di Malaysia tetapi juga di seluruh dunia. Industri ini telah mendominasi ekonomi negara di mana banyak lokasi menarik dijadikan tempat tarikan pelancongan, pelbagai produk dan jenama dihasilkan sebagai daya penarik dan penguat kepada industri pelancongan bagi sesebuah negara. Sejajar dengan perkembangan industri pelancongan sebagai pemangkin pembangunan sosio-ekonomi, adalah penting agar kerajaan meneruskan pembangunan pelancongan yang mampan secara menyeluruh dan terancang (Che Aziz, 2019). Justeru, Kementerian Pelancongan Malaysia (MOTAC) telah meningkat usaha mempergiat untuk mempromosikan Malaysia sebagai destinasi eko pelancongan terkenal khususnya dalam menarik pelancong yang cintakan alam sekitar dari seluruh dunia. Usaha untuk mempergiat kedatangan pelancong bagi segmen eko pelancongan ini bukan sahaja di tumpukan kepada negara-negara besar tetapi juga negara-negara lain termasuk negara jiran seperti Indonesia, Singapura dan Thailand walaupun bukan dalam skala yang besar (Ibrahim, Zainol, Awang, Fadzil, \& Edo, 2015)

Kekuatan pelancongan Malaysia bukan sahaja terletak pada produk eko pelancongan malah destinasi yang ditawarkan juga murah, selamat dan mudah untuk dikunjungi. Laporan berita harian pada tahun 2019 menyatakan bahawa impak sumbangan pelancongan di Malaysia dilihat konsisten dari tahun ke tahun walaupun kadangkala berlaku sedikit penurunan. Keadaan ini dapat dilihat daripada sumbangan pendapatan mengikut laporan prestasi kehadiran pelancong, perbelanjaan 
pelancong bagi tahun 2018 adalah sebanyak (RM84.1 bilion) berbanding (RM82.2 bilion) pada tahun 2017, yang mana ia menyaksikan peningkatan sebanyak 2.4 peratus. Tambahan lagi, mengikut data terkini, ramai pelancong dari Asia telah memasuki dan melancong dalam negara Malaysia dengan yang tertinggi dicatatkan adalah dari Singapura, Indonesia, China, Thailand, Brunei, Korea Selatan, India Australia, Filipina dan Jepun manakala United Kingdom merupakan negara Eropah tertinggi yang datang melancong ke Malaysia (Abidin \& Daud, 2020).

Malaysia mempunyai banyak tempat-tempat menarik bagi segmen eko pelancongan yang semakin diminati bukan sahaja di kalangan pelancong dalam negara malah juga dari luar negara yang ingin melihat keindahan alam sekitar serta menenangkan diri dari kesibukan kota. Produk eko pelancongan di Malaysia bukan sahaja dilihat sebagai satu aktiviti lasak tetapi juga sebagai pemangkin kepada kelestarian alam semulajadi. Secara dasarnya, Malaysia mempunyai pelbagai produk dan lokasi eko pelancongan yang sentiasa menjadi tumpuan pelancongan dalam dan luar negara. Sebagai contoh Hutan Lipur Sungai Sedim, Taman Negara Endau-Rompin, Hutan Simpan Royal Belum dan Gunung Stong, Dabong. Aktiviti eko pelancongan di Malaysia telah menjadi salah satu daya penarik khasnya kepada semua peminat aktiviti lasak. Justeru, adalah menjadi tanggungjawab dan kerjasama semua pihak sama ada pemain industri, pemegang taruh serta penduduk setempat untuk memastikan produk eko pelancongan di sesuatu kawasan itu sentiasa terpelihara dan terpulihara (Che Aziz, Hashim, \& Awang, 2018).

Pada tahun 1996, kerajaan Malaysia telah mewujudkan satu garis panduan khas berkenaan produk eko pelancongan iaitu Pelan Eko pelancongan Kebangsaan Malaysia 1996 (Malaysian National Eco-Tourism Plan 1996). Objektif utama garis panduan ini adalah untuk membantu kerajaan di peringkat kebangsaan dan negeri dalam membangunkan potensi eko pelancongan di Malaysia. Pelan ini digunakan sebagai satu instrumen yang bersesuaian dengan keseluruhan pembangunan kelestarian dan ekonomi di Malaysia secara menyeluruh. Selain iu, ia juga bertindak sebagai alat yang berkesan untuk pemeliharaan dan pemuliharaan sumber alam dan budaya warisan bagi sesebuah negara (WWF Malaysia, 1996). Walau bagaimanapun, setelah lebih 20 tahun pelaksanaan garis panduan ini di Malaysia, pihak Kementerian Pelancongan telah menambah baik dan menghasilkan satu garis panduan baharu iaitu Pelan Eko pelancongan Kebangsaan 2016-2025 (National Ecotourism Plan 2016-2025). Penubuhan pelan ini juga bertujuan untuk menilai semula kejayaan dan/ atau kekurangan yang berlaku semasa pelaksanaan Pelan Eko Pelancongan Kebangsaan 1996 serta mencadangkan beberapa prosedur dan polisi untuk meningkatkan perancangan, pengurusan kelestarian, pemeliharaan, kewangan dan promosi tapak eko pelancongan Malaysia (MOTAC, 2016).

\section{Kajian literatur}

Eko pelancongan merupakan satu pelancongan berasaskan alam semulajadi yang mempunyai potensi besar untuk berkembang di Malaysia yang sangat kaya dengan sumber biodiversiti. Produk ini telah menjadikan Malaysia berada di tempat ke-12 di dunia dari segi kemewahan biodiversiti. Kepelbagaian dan keunikan biodiverisiti di Malaysia telah menarik kedatangan ramai pelancong dari serata dunia (Mabul, Nor, Mayan, Nor, \& Sendut, 2016). Menurut Kementerian Pelancongan Malaysia, aktiviti eko pelancongan merupakan perjalanan dan/atau lawatan yang bertanggungjawab terhadap alam sekitar, kepada kawasan semulajadi untuk menikmati dan menyedari akan sifat-sifat semulajadi (termasuklah sifat-sifat kebudayaan kini dan masa lalu). Selain itu, ia juga menggalakkan pemuliharaan alam sekitar yang boleh membawa kesan yang 
memberangsangkan selain membolehkan penglibatan masyarakat tempatan di dalam aktiviti sosio-ekonomi yang positif (MOTAC, 2016). Secara dasarnya, penglibatan pelancong dalam aktiviti eko pelancongan adalah lebih berkisar kepada pendidikan dan kesedaran yang boleh menyumbang kepada pembangunan dan penjagaan alam sekitar (Kunjuraman \& Che Aziz, 2019).

Ramai pengkaji lalu menyifatkan konsep eko pelancongan merujuk kepada pelancongan yang berasaskan kepada alam semulajadi dan mereka melihat keupayaan alam semulajadi ini sebagai satu sumber daya tarikan utama kepada pelancong untuk berkunjung ke kawasan destinasi pelancongan berkenaan (Eco-Tour, 2010; Ibrahim, Zainol, Awang, Fadzil, \& Edo, 2015; Stoddard, Evans, \& Dave, 2008). Dalam kajian melalui Montaguti \& Mingotto (2015), menegaskan bahawa 'aktiviti eko pelancongan seharusnya memberi manfaat kepada pemuliharaan melalui peningkatan pengurusan kawasan semula jadi yang dikunjungi oleh pengunjung'. Manakala menurut Mackenbach et al., (2018) menyatakan bahawa ciri utama eko pelancongan adalah merangkumi faedah pemuliharaan, pengalaman berasaskan alam semula jadi dan penetapan faedah ekonomi dan sosial. Manakala Kunjuraman \& Hussin (2017) pula telah mengklasifikasikan eko pelancongan kepada lima ciri asas, iaitu (1) persekitaran semula jadi (kawasan terpelihara), (2) kelestarian ekologi, (3) pendidikan alam sekitar, (4) bermanfaat secara tempatan, dan (5) kepuasan pelancong. Ciri-ciri yang di sebutkan di atas harus di perhatikan dalam bentuk aktiviti pelancongan termasuk eko pelancongan.

Melalui satu kajian yang telah dijalankan oleh Ahmad dan Ibrahim (2006) di mana ia mengetengahkan beberapa ciri utama yang terkandung dalam konsep eko pelancongan iaitu (i) melibatkan kawasan yang 'bernilai' dan istimewa seperti hidupan liar, pemandangan, warisan dan keterasingan, (ii) meminimakan impak dan kerosakan kepada persekitaran tempatan dan komuniti, (iii) mendidik masayarakat supaya lebih memahami dan menghargai dan (iv) memaksimakan penglibatan, pengawalan dan manfaat kepada penduduk setempat. Selain Ahmad dan Ibrahim (2006), Eagels (1996) antara perintis dalam kajian eko pelancongan telah merumuskan tujuh prinsip eko pelancongan yang wajar dijadikan panduan. Prinsip-prinsip tersebut adalah seperti ditunjukan dalam Jadual 1.

Jadual 1. Faktor/ prinsip eko pelancongan

\begin{tabular}{cl}
\hline Bil & \multicolumn{1}{c}{ Faktor/ prinsip eko pelancongan } \\
\hline 1 & Melibatkan pemeliharaan alam semulajadi serta mampu menjana ekonomi tempatan \\
2 & $\begin{array}{l}\text { Pengusaha eko pelancongan pula perlu mengambilkira mengenai kebudayaan dan sensitiviti } \\
\text { masyarakat setempat }\end{array}$ \\
3 & $\begin{array}{l}\text { Pembangunan eko pelancongan juga perlu mengambil kira mengambil kira kebudayaan dan } \\
\text { sensiviti penduduk tempatan }\end{array}$ \\
4 & $\begin{array}{l}\text { Pelaksanaan eko pelancongan perlu memberi faedah kepada penduduk setempat sama ada dari } \\
\text { segi sosial, ekonomi atau sistem ekologi }\end{array}$ \\
5 & $\begin{array}{l}\text { Perlu perancngan pengurusan yang baik dan efisen } \\
6\end{array}$ \\
7 & $\begin{array}{l}\text { Penyebaran maklumat dan perkhidmatan yang berkuati tinggi } \\
\text { mengangunan eko pelancongan perlu mempunyai struktur pengurusan yang kukuh bagi }\end{array}$ \\
\hline
\end{tabular}
Sumber: Eagels (1996)

Manakala bagi sesebuah pembangunan pelancongan yang berjaya, Petrovska (2009, hal. 260) mencadangkan beberapa elemen yang harus dipertimbangkan sebagai berikut:

1. Mempunyai impak jangka panjang terhadap kawasan pemeliharaan sumber alam semulajadi 
2. Melibatkan pemegang taruh (individu, komuniti, pelancong eko, operator pengembaraan dan kerajaan ) dalam fasa perancangan, pembangunan, pelaksanaan dan pemantauan.

3. Menghormati tradisi dan budaya tempatan

4. Menjana kesaksamaan dan kelestarian pendapatan kepada penduduk setempat dan lain-lain pemegang taruh termasuk operator pengembaraan swasta, dan

5. Mendidik semua pemegang taruh terhadap peranan mereka dalam pemeliharaan dan pemuliharaan alam sekitar.

Kesedaran terhadap alam sekitar di kalangan masyarakat setempat di lihat sangat penting dalam usaha untuk memelihara sumber semula jadi dan kawasan sekitarnya. Ini kerana objektif utama pembangunan produk eko pelancongan adalah untuk mempromosikan usaha ke arah pemuliharaan di kalangan masyarakat setempat dan pengunjung bagi mengekalkan biodiversiti alam semula jadi bagi tempoh jangka panjang. Terdapat beberapa cadangan yang praktikal dibincangkan dalam kajian lepas bagi memastikan persekitaran sekitar lebih selamat dari sebarang bentuk manipulasi oleh pemegang taruh yang cuai dan tidak bertanggungjawab. Antara cadangan yang dibincangkan oleh Kunjuraman \& Che Aziz (2019) adalah seperti;

(i) Pihak berkepentingan pelancongan khususnya pihak kerajaan perlu mengemukakan atau menyediakan polisi baharu yang relevan dalam pembangunan eko pelancongan untuk meningkatkan kesedaran di kalangan masyarakat setempat dan pelancong.

(ii) Masyarakat setempat perlu menggunakan pengetahuan ekologi mereka yang dikenali sebagai "pengetahuan tradisional" untuk mengurangkan kesan negatif persekitaran dari pembangunan aktiviti pelancongan.

(iii) Para pelancong pula bertanggung jawab untuk melindungi alam sekitar dengan mengikuti peraturan dan undang-undang di destinasi eko pelancongan tempatan di dunia

Justeru, melalui kajian ini, konsep eko pelancongan boleh dirumuskan sebagai pelancongan alternatif yang banyak bergantung kepada kegiatan berasaskan alam semulajadi, dan penglibatan masyarakat setempat sangat penting untuk bertahan untuk masa depan dan memperoleh kejayaan tertinggi.

\section{Kawasan kajian}

Daerah Kulim terletak di bahagian selatan Negeri Kedah dan bersempadan dengan Daerah Seberang Perai Utara dan Tengah di Negeri Pulau Pinang. Daerah-daerah Negeri Kedah seperti Baling, Kuala Muda dan Bandar Baharu juga terletak bersempadanan dengan Daerah Kulim. Keluasan Daerah Kulim adalah 76,575.89 hektar dan ditadbir oleh dua pihak berkuasa tempatan iaitu Majlis Perbandaran Kulim dengan keluasan pentadbiran 75,091 hektar dan Pihak Berkuasa Tempatan Kulim Hi-tech Park 14.48 hektar yang hanya tertumpu di kawasan Kulim Hi-Tech Park sahaja. Dengan bilangan penduduk seramai 201,636 orang pada tahun 2000, kebanyakkan penduduk tertumpu di beberapa petempatan utama khususnya di Kulim, KHTP, Padang Serai, Sungai Seluang dan Lunas. Pertumbuhan penduduk juga telah mencapai 5.15\% antara tahun 1991 - 2000 iaitu kedua tertinggi di Negeri Kedah selepas Daerah Langkawi (Kulim District Council, 2013). 
Menurut Majlis Perbandaran Kulim, bandar Kulim sememangnya berpotensi menjadi salah sebuah destinasi pelancongan kerana disokong oleh wujudnya aset menarik seperti alam semulajadi dan sumber ekonomi sedia ada. Kajian mendapati bahawa terdapat 13 destinasi utama sedia ada. Di samping itu, terdapat 25 pembangunan komited yang di kenalpasti sebagai sumbersumber tarikan pelancongan di mana 17 adalah cadangan destinasi baru dan 8 untuk naik taraf. Pada tahun 2004 seramai 26,280 pelancong telah berkunjung ke KRT Kulim berdasarkan 40 peratus kadar penginapan hotel sedia ada. Pada tahun 2020 jumlah pelancong ke KRT Kulim diunjur akan bertambah kepada 109,500 pelancong melalui Pelan Strategi (2004-2020) yang dicadangkan (Kulim District Council, 2004). Terdapat dua jenis tarikan utama Daerah Kulim sedia ada iaitu Eko-lancong dan Agro-lancong (rujuk Jadual 2)

Jadual 2. Destinasi dan jenis tarikan pelancongan di bandar Kulim, Kedah

\begin{tabular}{|c|c|c|}
\hline Destinasi Pelancongan & Jenis Tarikan & Produk \\
\hline Air Terjun Sungai Sedim & $\begin{array}{l}\text { Eko-lancong dan } \\
\text { Agro-lancong }\end{array}$ & $\begin{array}{ll}\text { - } & \text { Alor/ sungai/ jeram/ hidupan akuatik } \\
\text { - } & \text { Kemudahan sukan; jeram sesuai untuk venue } \\
\text { - } & \text { acara (berakit/ berkayak arus deras) } \\
\text { - } & \text { Flora dan fauna } \\
\text { - } & \text { Pusat kursus atau bengkel } \\
\text { - } & \text { Pusat penginapan pelancong } \\
\text { - } & \text { Kawasan perusahaan pertanian }\end{array}$ \\
\hline Gunung Bintang & Eko-lancong & $\begin{array}{l}\text { - Hutan simpan/ bukit \& gunung/ gua/ flora \& fauna } \\
\text { - } \quad \text { Alor/ sungai/ jeram/ air terjun/ hidupan akuatik }\end{array}$ \\
\hline Ulu Paip & Eko-lancong & $\begin{array}{ll}\text { - } & \text { Alor/ sungai/ jeram / hidupan akuatik } \\
\text { - } & \text { Hutan simpan/ gunung/ flora \& fauna } \\
\text { - } & \text { Kawasan perusahaan pertanian } \\
\text { - } & \text { Pusat kursus/ bengkel }\end{array}$ \\
\hline Pahau & Eko-lancong & $\begin{array}{ll}\text { - } & \text { Hutan pelajaran/ pusat R\&D (tapak semaian) } \\
\text { - } & \text { Pusat kursus/ bengkel } \\
\text { - } & \text { Alor/ sungai/ hidupan akuatik } \\
\text { - } & \text { Hutan simpan/ gunung/ flora \& fauna }\end{array}$ \\
\hline Gunung Bongsu & Eko-lancong & $\begin{array}{l}\text { - } \text { Alor/ sungai/ hidupan akuatik } \\
\text { - Hutan simpan/ gunung/ flora \& fauna } \\
\text { - Kawasan perusahaan pertanian } \\
\text { - } \text { Pusat kursus/ bengkel } \\
\text { - Kawasan berperistiwa/ bersejarah }\end{array}$ \\
\hline $\begin{array}{l}\text { Kawasan Sawah Padi } \\
\text { Skim Sidam Kanan }\end{array}$ & Agro-lancong & $\begin{array}{ll}\text { - } & \text { Alor/ sungai/ hidupan akuatik } \\
\text { - } & \text { Kawasan petempatan desa } \\
\text { - } & \text { Hutan simpan/ gunung/ flora \& fauna } \\
\text { - } & \text { Kawasan perusahaan pertanian } \\
\text { - } & \text { Hidupan unggas/ burung hijrah }\end{array}$ \\
\hline
\end{tabular}

Sumber: Kulim District Council (2004); Kulim District Office (2011)

Selain daripada itu, menurut data yang di keluarkan juga menyatakan bahawa aktiviti sukan dan rekreasi merupakan sebahagian daripada penyumbang pembangunan sektor pelancongan Kulim di mana kemudahan sedia ada seperti mini Stadium Kulim, Taman Tasik Putra, Chinese Recreation Club, Kulim Golf and Country Resort, dan Kelab Golf Dublin telah menarik ramai pengunjung dari dalam dan luar negeri untuk menjalankan aktiviti mereka di sini. Menurut 
Kementerian Pelancongan Negeri Kedah, selain daripada Hutan Lipur Sungai Sedim di Kulim, Cruise Sungai Merbok, Sungai Petani juga telah dikenalpasti sebagai antara produk pelancongan terbaik di negeri Kedah dalam usaha menarik lebih ramai pelancong ke negeri itu (PEMANDU, 2009). Ini sekaligus dapat membantu industri pelancongan di Kedah untuk menyeimbangkan lagi bilangan pelancong dan kestabilan ekonomi kepada penduduk setempat. Kerajaan negeri juga akan meneruskan usaha untuk mempromosikan produk eko pelancongan di Kedah untuk memastikan pertumbuhan industri pelancongan di masa hadapan.

\section{Eko Pelancongan di Hutan Lipur Sungai Sedim, Kulim}

Hutan Lipur Sungai Sedim (HLSS), merupakan antara destinasi paling popular di daerah Kulim, Kedah yang mana menjadi lokasi kajian. Pemilihan HLSS adalah kerana ciri-ciri dan sumbangan masa depannya kepada semua pihak khasnya di kawasan berdekatan. Hutan Lipur Sungai Sedim telah di angkat sebagai salah satu "LIMA destinasi pilihan di Asia Fasifik" kerana mempunyai lebih daripada 24 arus deras air terjun sepanjang 15 kilometer (Kulim District Office, 2011). Lokasi HLSS yang terletak di bahagian utara semenajung Malaysia di negeri Kedah iaitu di kawasan Sedim yang berdekatan bandar Karangan, 30km dari bandar Kulim. Potensi HLSS untuk dijadikan salah sebuah destinasi eko pelancongan terbaik di Malaysia dapat di lihat daripada kekayaan alam semulajadi dan sumber hutan yang masih terpelihara. Antara contoh kehebatan HLSS adalah seperti air terjun Sungai Sedim berarus deras yang telah dikenali sebagai salah satu lokasi aktiviti White Water Rafting terbaik di Malaysia khasnya bagi peminat aktiviti lasak (Kulim District Council, 2013; Tourism Development Council, 2012).

Hutan Lipur Sungai Sedim ini juga dilengkapi dengan satu lagi produk yang unik iaitu Kanopi Pejalan Kaki Terpanjang Di Dunia (The World's Longest Tree Top Walk) yang dibina pada taun 2003 dan telah dirasmikan oleh Sultan Kedah. Pembinaan kanopi ini menelan belanja lebih RM250 juta dan diuruskan oleh syarikat atau konsultan khas dari Australia. Kanopi Pejalan Kaki Terpanjang Di Dunia dengan 925 meter panjang dan 50 meter tinggi atau di kenali dengan Tree Top Walk (TTW) adalah aset terpenting dan termahal yang terdapat di HLSS. Kanopi ini menawarkan pemandangan indah semulajadi dengan kepelbagaian sumber hutan yang menghijau adalah aktiviti yang paling menarik yan terdapat di HLSS (Kulim District Council, 2013) di samping pemeliharaan terhadap elemen jejak warisan. Pelbagai aktiviti dapat dilakukan di kawasan kanopi ini seperti berjalan kaki sambil menikmati suasana hutan yang menghijau, aktiviti melihat burung (bird-watching) dan pendidikan pelancongan (Kulim District Office, 2014). Tambahan lagi, dengan kombinasi kepelbagaian sumber alam seperti taman rekreasi, gunungganang serta aktiviti hutan menjadikan HLSS sebagai satu salah destinasi tarikan pelancong sama ada dari dalam mahupun dari luar negara. Bagi peminat aktiviti lasak seperti kayak, rafting dan water abseiling, HLSS menyediakan trek atau laluan air terjun yang berarus deras dan mencabar. 


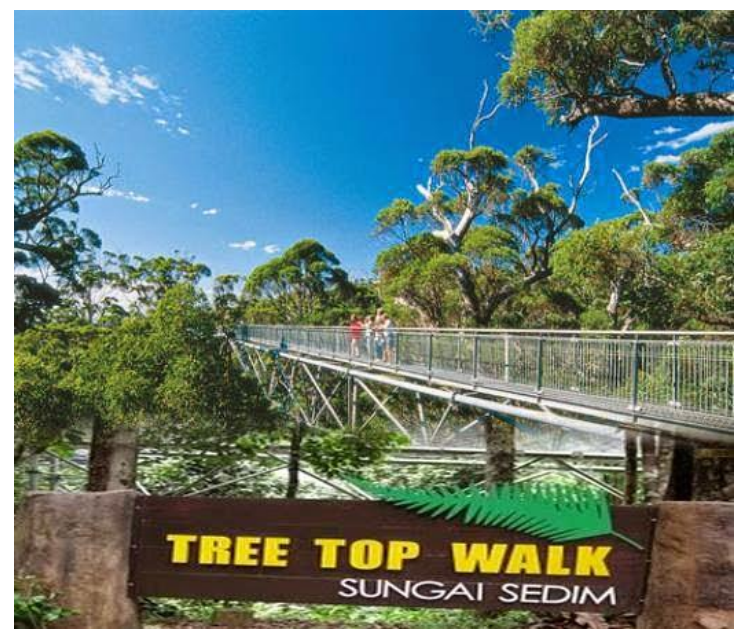

Sumber: Kulim District Council (2004)

Rajah 1: Top Walk di Hutan Lipur Sungai Sedim

Satu isu yang sering menjadi perhatian dan perbincangan banyak pihak terhadap prospek dan pembangunan masa hadapan di Hutan Lipur Sungai Sedim adalah produk alam semulajadi yang dimiliki seperti keindahan air terjun dan keaslian sumber alam. Antara usaha dan sokongan yang ditunjukkan oleh pihak kerajaan negeri terhadap pembangunan HLSS adalah dengan menyediakan peruntukan untuk membaiki dan membina fasiliti dan kemudahan baharu, membina gazebo untuk kegunaan pelancong serta menaik taraf pelbagai infrastruktur lain untuk menarik lebih ramai pelancong. Usaha ini dilihat sebagai salah satu proses dan alat untuk pertumbuhan ekonomi yang dapat merancakkan lagi saluran perniagaan dan keusahawanan khasnya di kawasan luar bandar (Keyim, Yang \& Zhang, 2005). Penubuhan pelbagai aktiviti dan produk seperti Jambatan gantung terpanjang di dunia serta pelbagi aktiviti sukan lasak telah menyebabkan HLSS dibangunkan sebagai destinasi berasaskan alam semulajadi dan telah membuka fenomena baru khasnya kepada peminat aktiviti eko pelancongan.

Justeru, pembangunan produk eko pelancongan di HLSS perlu diberi perhatian secara serius bagi memastikan tiada kemusnahan alam berlaku akibat aktiviti pelancongan dan keghairahan manusia dalam meneroka sumber sedia ada. Beberapa perkara lain yang amat penting untuk pembangunan pelancongan di HLSS sebagai salah satu produk terpenting di Kedah adalah untuk mewujudkan garis panduan dan objektif pembangunan pelancongan serta meningkatkan taraf sosial penduduk setempat dan operator pelancongan. Ini kerana pembangunan pelancongan di sesuatu kawasan dilihat dapat membuka banyak ruang dan peluang selain kebaikan kepada penduduk sekitar seperti pembangunan infrastruktur dan peluang perniagaan kecil-sederhana (Ibrahim \& Ahmad, 2008). Dalam konteks ini, pembangunan lestari adalah alat atau alternatif terbaik untuk dilaksanakan dan diaplikasikan dalam mana-mana pembangunan pelancongan luar bandar seperti di kawasan Sedim.

Menyedari produk eko pelancongan semakin mendapat perhatian dan permintaan daripada pelancong dan pemegang taruh dalam industri pelancongan di Malaysia, maka usaha mempergiat dan mempromosi produk eko pelancongan terus dipertingkatkan. Keunikan dan kekayaan alam semulajadi yang dimiliki khasnya di Hutan Lipur Sungai Sedim, Kulim Kedah ini terus mendapat perhatian dan tindakan pelbagai pihak termasuk badan bukan kerajaan (NGO) untuk dipromosikan sebagai produk eko pelancongan terkenal di dunia. Walau bagaimanapun, terdapat beberapa isu 
dan masalah yang perlu ditangani dalam memajukan sektor pelancongan di HLSS khasnya dan negeri Kedah umumnya iaitu:-

1. Cabaran dan daya saing dari kawasan sempadan seperti Daerah Seberang Perai (Pulau Pinang), Daerah Kuala Muda, dan Daerah Kerian.

2. Pemasaran pelancongan semasa kurang meluas, cekap dan berkesan di mana penawaran destinasi, produk dan program pelancongan sedia ada adalah terhad dan kurang daya tarikan.

3. Penyediaan kemudahan pelancongan yang terhad dan tidak memenuhi kehendak pengunjung atau kualiti kemudahan.

4. Koordinasi antara agensi masih terhad dan tiada matlamat secara bersama dalam memajukan sektor pelancongan.

5. Wujud tekanan keperluan pelaburan, kesediaan sumber manusia, alam sekitar dan penduduk setempat dalam melaksanakan pembangunan pelancongan.

Pembangunan HLSS sebagai satu salah destinasi pelancongan eko di Kedah di lihat mampu menarik ramai pelancong sama ada dari luar negara atau domestik sekaligus mampu membuka banyak peluang pekerjaaan kepada penduduk setempat seperti perniagaan makanan dan minuman, kraftangan, penginapan dan inap desa. Banyak pengusaha produk eko pelancongan di HLSS mampu membuka ruang dan peluang kepada generasi belia dan penduduk setempat untuk menjana pendapatan dan meneroka bidang baharu dalam industri pelancongan eko. Justeru, kajian ini dilakukan di kawasan HLSS kerana melihat potensi baru pembangunan produk eko pelancongan rekreasi yang mana masih belum diteroka dan dikaji oleh penyelidik lain. Timbul juga keperluan untuk mengkaji dan melihat sejauhmana HLSS berpotensi untuk di angkat sebagai salah satu destinasi produk eko pelancongan terkenal. Adakah kemudahan dan fasiliti yang disediakan di HLSS mampu menarik kehadiran pelancong selain memberikan keselesaan dan kepuasan kepada mereka? Apakah persepsi dan cadangan pemegang taruh di HLSS dalam memajukan HLSS sebagai salah sebuah destinasi eko pelancongan terkenal di dunia?

\section{Metod}

Pendekatan kajian adalah berfokus kepada kualitatif yang mana menggabungkan tiga jenis kaedah iaitu secara perbincangan kumpulan (focus group discussion), pemerhatian (observation) dan temubual tidak berstruktur (semi-structured interview) terhadap responden yang dipilih (rujuk Jadual 3). Data kajian diperoleh melalui pengumpulan data primer dan data sekunder. Manakala, data sekunder dalam kajian ini adalah melalui data yang diperolehi daripada jabatan kerajaan iaitu Pejabat Daerah Kulim, Pejabat Tanah Daerah Kulim dan Kementerian Pelancongan Alor Setar. Temubual secara tidak berstruktur dijalankan bersama 12 orang pelancong yang telah dipilih secara rawak yang menjadikan Hutan Lipur Sungai Sedim sebagai lokasi percutian mereka. Responden kajian ini adalah terdiri daripada komuniti tempatan atau penduduk sekitar, pengusaha resort atau aktiviti rekreasi, pihak berkepentingan negeri serta pelancong yang menginap dan melakukan aktiviti di HLSS.

Selain itu, pemilihan responden ini adalah secara bertujuan (purposive sampling) bagi memastikan segala maklumat dan perasaan yang disampaikan adalah tepat dengan situasi dan keadaan responden terhadap potensi pelancongan di HLSS. Salah satu prinsip persampelan dalam 
penyelidikan kualitatif adalah berhenti temubual pada titik "tepu" (saturated). Prinsip ini di ikuti apabila di setiap kumpulan responden sudah tiada lagi responden baru yang ditemu ramah kerana penyelidik merasakan tiada lagi informasi baru yang diperoleh daripada soalan-soalan yang disediakan. Justeru, kajian mendapati bahawa seramai 59 orang responden telah melibatkan diri dalam membantu mendapatkan maklumat daripada kajian ini. Jadual berikut adalah maklumat berkenaan jenis dan bilangan responden terlibat:

Jadual 3. Jenis dan bilangan responden kajian yang terlibat

\begin{tabular}{|c|c|c|c|c|}
\hline No & Kategori & Profil responden & Bilangan & $\begin{array}{c}\text { Kaedah } \\
\text { pendekatan }\end{array}$ \\
\hline 1 & Penduduk & $\begin{array}{l}\text { Penduduk setempat (belia \& penduduk } \\
\text { sekitar HLSS) }\end{array}$ & 35 & $\begin{array}{l}\text { Perbincangan } \\
\text { kumpulan }\end{array}$ \\
\hline 2 & $\begin{array}{l}\text { Pihak } \\
\text { berkepentingan }\end{array}$ & $\begin{array}{l}\text { Pakar atau pihak kerajaan yang terlibat } \\
\text { dalam pembangunan dan perancangan } \\
\text { HLSS peringkat negeri dan daerah }\end{array}$ & 5 & $\begin{array}{l}\text { Temubual tidak } \\
\text { berstruktur }\end{array}$ \\
\hline 3 & $\begin{array}{l}\text { Operator } \\
\text { pelancongan }\end{array}$ & $\begin{array}{l}\text { Operator yang mengendalikan aktiviti, } \\
\text { menguruskan perniagaan dan } \\
\text { menyediakan pakej }\end{array}$ & 7 & $\begin{array}{l}\text { Temubual tidak } \\
\text { berstruktur }\end{array}$ \\
\hline \multirow[t]{2}{*}{4} & $\begin{array}{l}\text { Pengunjung/ } \\
\text { pelancong }\end{array}$ & Domestik dan antarabangsa & 12 & $\begin{array}{c}\text { Temubual tidak } \\
\text { berstruktur }\end{array}$ \\
\hline & & Jumlah responden & 59 & \\
\hline
\end{tabular}

Sumber: Kajian penyelidik (2019)

Kajian ini telah dijalankan selama tiga bulan di mana segala prosedur kajian telah disediakan terlebih dahulu sebelum proses temubual dilakukan. Seorang perantara (gatekeeper) telah dilantik bagi memastikan proses pengumpulan data dapat dilakukan mengikut prosedur yang ditetapkan. Borang perakuan diri (consent form) diberikan kepada semua responden sebelum sesi temubual dijalankan. Setiap sesi temubual secara bersemuka mengambil masa di antara 20 hingga 40 minit bergantung kepada kategori responden. Video dan rakaman suara telah digunakan bagi memastikan data dapat dianalisa dengan tepat dan jelas. Aplikasi Atlas.ti telah digunakan sebagai alat untuk mengalisa data yang telah diterjemah di mana proses penyusunan tema dan kategori dilakukan untuk mendapatkan hasil dapatan.

\section{Hasil kajian}

Hutan Lipur Sungai Sedim di lihat semakin berkembang dan berkemampuan untuk menawarkan dan mempromosikan pelbagai produk eko pelancongan seperti white-water rafting serta keindahan alam dan flora fauna. Semua aktiviti yang ditawarkan ini memfokuskan kepada peminat tegar sukan lasak, di mana memberikan tahap kepuasan dan pengalaman luar biasa kepada pengunjung khasnya melalui aktiviti Tree Top Walk dan Air Terjun Air Deras di HLSS. Hasil kajian ini mendapati bahawa terdapat potensi dan sumbangan secara langsung dan secara tidak langsung yang terhasil daripada kewujudan dan pembangunan pelancongan eko pelancongan di HLSS. Berdasarkan kepada analisa yang dijalankan kepada semua responden tersebut, satu kritikal faktor kejayaan (critical success factor) terhadap Hutan Lipur Sungai Sedim (HLSS) telah dikenalpasti iaitu pembangunan produk berkonsep (niche product). Terdapat juga beberapa faktor yang dikenalpasti sebagai potensi HLSS untuk dipromosikan dan dibangunkan sebagai produk 
pelancongan eko pelancongan dan juga produk luar bandar di Malaysia. Penduduk setempat juga turut mendapat tempias dan kesan pengaruh yang di bawa oleh peningkatan dan pembangunan industri pelancongan di HLSS.

Melalui kajian ini, semua responden diberikan peluang untuk menyuarakan hasrat dan pandangan mereka berdasarkan pengalaman dan pemerhatian terhadap interaksi bersama pelancong/ pengunjung serta aktiviti pelancongan yang berlaku di HLSS. Hasil cerapan pemerhatian dan pandangan semua responden mendapati:

Jadual 4. Ringkasan hasil dapatan berkenaan potensi dan peluang industri pelancongan di Hutan Lipur Sungai Sedim

\begin{tabular}{|c|c|c|c|c|}
\hline & \multicolumn{4}{|c|}{ KUMPULAN RESPONDEN } \\
\hline & $\begin{array}{c}\text { Penduduk setempat \& } \\
\text { belia kampong }(L C)\end{array}$ & $\begin{array}{l}\text { Pihak kerajaan } \\
\text { (LA) }\end{array}$ & $\begin{array}{c}\text { Operator } \\
\text { Pelancongan }(T O)\end{array}$ & $\begin{array}{c}\text { Pengunjung/ } \\
\text { pelancong }(V S)\end{array}$ \\
\hline $\begin{array}{c}\text { Tema } \\
\text { Utama }\end{array}$ & \multicolumn{3}{|c|}{ Produk berkonsep (Niche products) } & $\begin{array}{l}\text { Pembangunan } \\
\text { infrastruktur dan } \\
\text { fasiliti }\end{array}$ \\
\hline \multirow[t]{4}{*}{$\begin{array}{c}\text { Tema } \\
\text { sampingan }\end{array}$} & $\begin{array}{l}\text { Program Inap desa } \\
\text { (Home-stay) }\end{array}$ & $\begin{array}{l}\text { Pembangunan } \\
\text { infrastruktur dan } \\
\text { fasiliti }\end{array}$ & $\begin{array}{l}\text { Pembangunan } \\
\text { keusahawanan luar } \\
\text { bandar }\end{array}$ & $\begin{array}{l}\text { Produk berkonsep } \\
\text { (Niche products) }\end{array}$ \\
\hline & $\begin{array}{l}\text { Pusat pendidikan dan } \\
\text { penyelidikan }\end{array}$ & $\begin{array}{l}\text { Program Home- } \\
\text { stay }\end{array}$ & $\begin{array}{l}\text { Pusat pendidikan dan } \\
\text { penyelidikan }\end{array}$ & $\begin{array}{l}\text { Pembangunan } \\
\text { keusahawanan luar } \\
\text { bandar }\end{array}$ \\
\hline & $\begin{array}{l}\text { Pembangunan } \\
\text { keusahawanan luar } \\
\text { bandar }\end{array}$ & $\begin{array}{l}\text { Pusat pendidikan } \\
\text { dan penyelidikan }\end{array}$ & Program Home-stay & $\begin{array}{l}\text { Pusat pendidikan dan } \\
\text { penyelidikan }\end{array}$ \\
\hline & $\begin{array}{l}\text { Nilai budaya, sejarah } \\
\text { dan seni bina }\end{array}$ & $\begin{array}{l}\text { Pembangunan } \\
\text { keusahawanan luar } \\
\text { bandar }\end{array}$ & $\begin{array}{l}\text { Pembangunan } \\
\text { infrastruktur dan } \\
\text { fasiliti }\end{array}$ & \\
\hline
\end{tabular}

Sumber: Kajian penyelidik (2019)

\section{Peluang dan potensi utama Hutan Lipur Sungai Sedim sebagai produk eko pelancongan}

\section{a. Mempromosikan Produk Pasaran Berkonsep (Niche Products Market)}

Berdasarkan kepada hasil dapatan kajian iaitu melalui sesi temubual dan perbincangan kumpulan bersama semua responden, terdapat beberapa potensi dan peluang untuk HLSS diangkat sebagai produk eko pelancongan terkemuka di Malaysia. Seperti hasil dapatan di Jadual 4 menunjukkan potensi untuk mempromosikan produk pasaran berkonsep (niche products market) sebagai tema utama yang diutarakan oleh semua responden. Penduduk tempatan dan juga operator pelancongan yang terlibat secara langsung dalam aktiviti pelancongan di HLSS akan sentiasa mencari produkproduk baharu yang boleh menarik pelancong luar sekaligus dapat menambahkan sumber pendapatan mereka. Sumber alam semulajadi (seperti air terjun, gunung-ganang dan flora fauna), budaya dan warisan serta lanskap adalah antara jenis sumber yang berharga di HLSS. Semua sumber yang dinyatakan digabungkan bersama dengan tren pasaran terbuka terhadap produk 
berkonsep (niche market) boleh dijadikan sumber persaingan kelebihan (competitive advantage) kepada produk eko pelancongan di HLSS dan menjadi sumber utama yang perlu diangkat dan diiktiraf sama ada di peringkat nasional atau antarabangsa. Ini akan mengangkat nama HLSS, memberi nilai pendapatan yang tinggi selain dapat menyediakan peluang pekerjaan kepada penduduk setempat dan golongan belia kampung. Operator pelancongan di HLSS juga mempunyai peluang untuk menjual dan menghasilkan lebih banyak produk tempatan dan sekaligus dapat meningkatkan potensi pasaran dan jualan produk. Secara langsung dapat meningkatkan keuntungan dan peluang perniagaan kepada semua penduduk di sekitar kawasan Sungai Sedim.

\section{b. Potensi untuk pembangunan infrastruktur dan fasiliti}

Hutan Lipur Sungai Sedim telah dikenalpasti mempunyai pelbagai sumber kekayaan yang melibatkan bukan hanya kekayaan alam semulajadi, flora dan fauna tetapi juga lebih kepada kekayaan sumber budaya dan warisan yang dimiliki. Kedudukan bandar Sedim yang tidak jauh dari bandar terkenal di Kedah iaitu Kulim dan Butterworh, Pulau Pinang, menjadikan HLSS sebagai salah satu daya tarikan utama pelancongan dan pengunjung dari bandar-bandar terdekat. Hasil kajian mendapati, pihak kerajaan telah menyediakan peruntukan khas atau dana kepada pembangunan fasiliti dan infrastruktur khasnya dalam membangunkan kawasan air terjun Sungai Sedim. Ini bertujuan untuk memastikan pembangunan aktiviti pelancongan di HLSS dapat terus bertahan dan meningkat dari masa ke semasa dengan penyediaan kemudahan yang lebih selesa dan tersusun kepada para pelancong. Potensi pembangunan fasiliti dan kemudahan seperti gazebo, tandas awam, tempat persalinan serta surau akan menjadikan HLSS lebih terkenal dan menarik lebih ramai pengunjung sekaligus dapat membantu pertumbuhan ekonomi penduduk setempat.

\section{c. Mempromosikan program Inap desa (Home-stay)}

Komponen utama program inap desa (home-stay) yang dibangunkan oleh Kementerian Pelancongan Malaysia yang berbeza dengan program inap desa (home-stay) di negara lain adalah elemen yang berkonsep "tinggal bersama" di antara pelancong dan tuan rumah yang di kenali sebagai "keluarga angkat" (Kayat, 2011; Razzaq et al., 2011). Elemen ini melibatkan tetamu/ pelancong akan makan, memasak dan melakukan pelbagai aktiviti bersama-sama dengan tuan rumah/ keluarga angkat di mana kedua-dua pihak mempunyai latar-belakang yang berbeza tetapi perlu berinteraksi dan belajar bersama-sama. Berdasarkan kepada situasi ini, hasil kajian ini mendapati bahawa majoriti responden terutamanya penduduk setempat sememangnya aktif dan mengiktiraf program inap desa (home-stay) ini sebagai salah satu sumber pendapatan kepada mereka. Pada masa ini, aktiviti inap desa yang dijalankan di Kampung Sungai Sedim tidak didaftarkan di bawah Kementerian Pelancongan Malaysia dan tidak mengikut standard prosedur yang ditetapkan. Justeru, adalah penting untuk menjadikan program home-stay ini lebih formal dan diiktiraf di peringkat kementerian demi kebaikan semua pihak yang terlibat. Di samping itu, melalui pembangunan program inap desa ini dapat mempromosikan budaya dan warisan yang dimiliki oleh Kampung Sedim selain dapat membantu meningkatkan sumber ekonomi penduduk setempat dan golongan belia. 


\section{d. Pembangunan Keusahawanan Luar Bandar (perniagaan, kemahiran \& kraftangan)}

Selain daripada peluang dan potensi yang disediakan secara tidak formal, terdapat juga pelbagai peluang perniagaan yang boleh diwujudkan di Hutan Lipur Sungai Sedim. Sebagai contoh menyediakan latihan kepada peminat sukan lasak (water-rafting di Sungai Sedim), latihan budayaagro (agro-culture) di bandar Kulim, kemudahan pengangkutan awam serta mewujudkan perkhidmatan katering untuk memperkenalkan makanan tempatan. Terdapat juga pelbagai peluang perniagaan lain yang dapat meningkatkan sumber ekonomi penduduk tempatan dan operator pelancongan seperti perkhidmatan dobi layan diri berdekatan HLSS, pusat hiburan serta pelbagai aktiviti eko pelancongan lasak. Dalam situasi ini, kajian lepas melihat kepentingan inovasi sebagai pemangkin kepada pertumbuhan dan kelebihan daya saing selain proses merebut peluang perlu diwujudkan untuk melihat perubahan (Carlisle, Kunc, Jones \& Tiffin, 2013; Cosma et al., 2014)..

\section{Perbincangan dan cadangan}

Daripada sorotan kajian literatur dan dapatan kajian, adalah ditegaskan bahawa penglibatan dan penyertaan penduduk tempatan dalam aktiviti pelancongan di Hutan Lipur Sungai Sedim sememangnya dapat membantu mereka untuk berkongsi segala pengalaman dan kebaikan yang dimiliki demi pembangunan pelancongan sama ada dari sudut ekonomi mahupun budaya. Satu perkara yang amat jelas di lihat dari sudut potensi pelancongan di HLSS adalah kepentingan ekonomi untuk terus mempromosikan industri pelancongan di HLSS terutamanya dalam aktiviti eko pelancongan demi kepentingan dan kebaikan semua penduduk. Hal ini termasuklah membuka peluang pekerjaan kepada golongan belia khasnya serta meningkatkan lagi pendapatan operator pelancongan yang menyediakan perkhidmatan dan produk kepada pelancong. Sesetengah responden melalui kajian ini mendapati dengan perkembangan industri pelancongan di HLSS, banyak peluang potensi lain juga dapat diwujudkan dan di manfaatkan oleh semua pihak.

Pelbagai produk dan perkhidmatan dapat ditawarkan kepada pelancong seperti aktiviti lasak eko pelancongan dan program inap desa iaitu memperkenalkan aktiviti mendaki Gunung Inas selain aktiviti silat dan marhaban yang menjadi budaya penduduk setempat. Majoriti responden juga amat mengharapkan dan ingin melihat lebih banyak kemudahan dan fasiliti disediakan khasnya untuk menggalakan kedatangan pelancong dan pengunjung ke HLSS. Terdapat hubungan yang positif di antara tahap penglibatan penduduk setempat dalam pembangunan pelancongan dan sokongan mereka terhadap peningkatan pembangunan pelancongan (Hussin \& Kunjuraman, 2014). Ini jelas dapat dilihat daripada maklumbalas penduduk dan operator pelancongan yang ingin melihat lebih banyak produk pelancongan dan kemudahan diperkenalkan untuk menarik lebih ramai pelancong ke HLSS. Selain itu, dalam perubahan persekitaran dan ekonomi pertanian tradisional yang berlaku di HLSS, adalah penting untuk mencari alternatif baharu kepada perkhidmatan dan sokongan oleh pihak operator pelancongan di HLSS.

Peranan pihak kerajaan pula adalah untuk merangsang dan mewujudkan persekitaran yang sesuai dengan keadaan di Hutan Lipur Sungai Sedim. Lebih penting lagi adalah untuk menumpukan kepada mana-mana pihak yang mempunyai motivasi dan kewangan yang kukuh selain kemahiran yang sesuai untuk memulakan aktiviti dan perkhidmatan yang relevan kepada pelancong. Tambahan lagi, kajian lepas juga menyarankan agar usaha keras perlu dilakukan dan diselaraskan di kalangan penduduk untuk mewujudkan budaya keusahawanan dan membina kapasiti untuk sentiasa mengambil peluang yang ada (Fortunato, 2014). Demi memastikan 
penyelarasan aktiviti dan program pelancongan di sesuatu kawasan dapat dilakukan dengan teratur dan terancang, adalah amat penting untuk memastikan semua pemegang taruh (penduduk tempatan, pihak kerjaan dan penyedia perkhidmatan) agar bersama-sama dan saling memahami peranan masing-masing (Bramwell \& Lane, 2012; Cosma et al., 2014) di samping dapat memastikan kelestariakan pembangunan pelancongan sentiasa dilaksanakan.

\section{Kesimpulan}

Artikel ini menunjukkan bahawa terdapat pelbagai potensi dan peluang untuk pembangunan produk eko pelancongan di Hutan Lipur Sungai Sedim, Kulim, Kedah. Penerokaan destinasi ini sebagai salah satu lokasi pelancongan luar bandar telah lama berlaku namum masih ramai yang kurang mengetahui tentang kewujudan lokasi ini. Kewujudan jambatan terpanjang di dunia iaitu Tree Top Walk di lihat mampu mengangkat nama HLSS sebagai salah satu destinasi eko pelancongan terkemuka di Malaysia dan di dunia. Berdasarkan hasil kajian yang diperoleh, penduduk tempatan di HLSS sudah bersedia untuk menerima kedatangan pelancong dan juga pembangunan pelancongan di kawasan tersebut walaupun tahap penerimaan mereka terhadap industri tersebut masih lagi berada pada kadar yang sederhana.

Di samping itu, hasil kajian ini juga mendapati harapan dan cadangan daripada penduduk tempatan mengenai industri pelancongan perlu diambil perhatian demi memastikan perkongsian manfaat dan sumber ekonomi dapat dikongsi dan dirasai bersama oleh semua pihak. Responden kajian juga mengharapkan dan mencadangkan agar pelbagai kemudahan awam di kawasan HLSS dapat diberi nafas baru bagi melaksanakan matlamat tersebut. Berdasarkan kajian literatur juga, pembangunan luar bandar dan eko pelancongan secara umumnya amat komplek tetapi amat bernilai untuk membangunkan sumber ekonomi penduduk setempat. Ia juga menyumbangkan kepada pelbagai penyelesaian masalah yang dihadapi oleh penduduk setempat selain dapat meningkatkan pendapatan setempat serta menggalakan lebih ramai pelancong datang ke HLSS. Walau bagaimanapun, adalah amat penting agar semua pemegang taruh yang terlibat dalam industri pelancongan di HLSS untuk terus bekerjsama dan bersatu hati dalam usaha menaikkan lagi nama HLSS dan meningkatkan lebih banyak produk untuk ditawarkan kepada pelancong. Ini selaras dengan misi dan objektif Kementerian Pelancongan Malaysia untuk terus meningkatkan produk eko pelancongan selain menarik lebih ramai pelancong ke destinasi eko pelancongan di Malaysia.

\section{Rujukan}

Abidin, M. F. Z., \& Daud, R. (2020, March 31). Ekopelancongan jadi pilihan pelancong. Star Harian. Retrieved from https://www.sinarharian.com.my/article/20995/BERITA/Nasional/ Ekopelancongan-jadi-pilihan-pelancong

Bramwell, B., \& Lane, B. (2012). Towards innovation in sustainable tourism research ? Journal of Sustainable Tourism, 20(1), 1-7.

Carlisle, S., Kunc, M., Jones, E., \& Tiffin, S. (2013). Supporting innovation for tourism development through multi-stakeholder approaches: Experiences from Africa. Tourism Management, 35, 59-69.

Che Aziz, R. (2019). S.O.A.R Analysis: A New Model for the Strategic Sustainable Tourism 
Development and Special Interest Tourism. In J. H. Costa (Ed.), The Special Interest Tourism in Southeast Asia (Vol. 8, pp. 107-131). Turismo: Estudos \& Práticas (RTEP/UERN), Mossoró/RN.

Che Aziz, R., Hashim, N. A. A. N., \& Awang, Z. (2018). Tourism development in rural areas: potentials of appreciative inquiry approach. Journal of Tourism, Hospitality \& Culinary Arts, 10(1), 59-75.

Cosma, S., Paun, D., Bota, M., \& Fleseriu, C. (2014). Innovation-A useful tool in the rural tourism in Romania. Procedia - Social and Behavioral Sciences, 148, 507-515.

Eco-Tour. (2010). Eco-Tourism. Retrieved June 1, 2012, from http://www.ecotourdirectory.com/responsible-travel.htm

Fortunato, M. W.-P. (2014). Supporting rural entrepreneurship: A review of conceptual developments from research to practice. Community Development, 45(4), 387-408.

Hashim, N. A. A. N., Yusoff, A. M., Awang, Z., Che Aziz, R., Ramlee, I. F., Bakar, N. A., ... Fatt, B. S. (2019). The Effect of Domestic Tourist Perceived Risk on Revisit Intention in Malaysia. International Journal of Innovative Technology and Exploring Engineering (IJITEE), 8(10), 4591-4596. https://doi.org/10.35940/ijitee.J1085.0881019

Hussin, R., \& Kunjuraman, V. (2014). Sustainable community-based tourism ( Cbt ) through homestay programme in Sabah, East Malaysia. Proceeding of the Social Sciences Research ICSSR 2014 (e-ISBN 978-967-11768-7-0). 9-10 June 2014, Kota Kinabalu, Sabah, MALAYSIA.

Ibrahim, J. A., \& Ahmad, M. Z. (2008). Pelancongan Negeri Kedah Darul Aman: Isu dan Cabaran. In Persidangan Kebangsaan Ekonomi Malaysia ke III (PERKEM III) (Vol. 1, pp. 191-202). Malaysia: Universiti Utara Malaysia Press.

Ibrahim, W. S. W., Zainol, R., Awang, S. N., Fadzil, K. S., \& Edo, J. (2015). Tourism and local development in Malaysia: A SWOT analysis of the Royal Belum as an eco-tourism product. GEOGRAFIA - Malaysian Journal of Society and Space Malaysian Journal of Society and Space, 11(13), 115-130.

Kayat, K. (2011). Homestay programme as Malaysian product. Malaysia: Universiti Utara Malaysia Press.

Keyim, P., Yang, D., \& Zhang, X. (2005). Study of rural tourism in Turpan, China. Chinese Geographical Science, 15(4), 377-382.

Kulim District Council. (2004). Rancangan Tempatan Daerah Kulim 2004-2020. Malaysia.

Kulim District Council. (2013). Official Website of Kulim Municipal Council. Retrieved April 20, 2013, from http://www.mpkk.gov.my/web/guest/kulim_district_tourism

Kulim District Office. (2011). Pelancongan Kulim. Retrieved July 20, 2012, from http://lamanwebpejabatdaerahkulim.blogspot.com/

Kulim District Office. (2014). The Tree Top Walk. Retrieved May 10, 2014, from http://webjabatan.kedah.gov.my/pdk.php

Kunjuraman, V., \& Che Aziz, R. (2019). Community-Based Ecotourism (Cbe) Development in Lower Kinabatangan of Sabah, Malaysian Borneo. In J. H. Costa (Ed.), The Special Interest Tourism in Southeast Asia (Vol. 8, pp. 13-43). Turismo: Estudos \& Práticas (RTEP/UERN), Mossoró/RN.

Kunjuraman, V., \& Hussin, R. (2017). Challenges of community-based homestay programme in Sabah, Malaysia: Hopeful or hopeless? Tourism Management Perspectives. https://doi.org/10.1016/j.tmp.2016.10.007

Mabul, D. A. N. P., Nor, S., Mayan, A., Nor, R. M., \& Sendut, P. H. (2016). Prospek dan cabaran 
sektor ekopelancongan dalam membasmi kemiskinan di Sabah: Kes Orang Utan dan Pulau Mabul. International Journal of Environment, Society and Space, 4(1), 17-28.

Mackenbach, J. D., Matias de Pinho, M. G., Faber, E., den Braver, N., de Groot, R., Charreire, H., ... Lakerveld, J. (2018). Exploring the cross-sectional association between outdoor recreational facilities and leisure-time physical activity: The role of usage and residential self-selection. International Journal of Behavioral Nutrition and Physical Activity, 15(1), 111. https://doi.org/10.1186/s12966-018-0689-x

Montaguti, F., \& Mingotto, E. (2015). Ecotourism in Natural Parks: An assured sustainable success? Tourist behavior, attractiveness and sustainable development issues in Two Italian Parks. Tourism Planning \& Development, 12(1), 99-110.

MOTAC. (2016). National Ecotourism Plan 2016-2025. Kuala Lumpur, Malaysia.

PEMANDU. (2009). Chapter 10- Reviving Up the Tourism Industry. Malaysia.

Razzaq, A. R. A., Hadi, M. Y., \& Mustafa, M. Z. (2011). Local community participation in homestay program development in Malaysia. Journal of Modern Accounting and Auditing, 7(12), 1418-1429.

Stoddard, J. E., Evans, M. R., \& Dave, D. S. (2008). Sustainable tourism: The case of the Blue Ridge National Heritage Area. Cornell Hospitality Quarterly, 49(3), 245-257. Retrieved from http://cqx.sagepub.com/cgi/doi/10.1177/1938965508320574

Tourism Development Council. (2012). Tourism Malaysia corporate website. Retrieved September 21, 2012, from http://corporate.tourism.gov.my/aboutus.asp

WWF Malaysia. (1996). Pelan Ekopelancongan Kebangsaan Malaysia. Kuala Lumpur, Malaysia. 